\title{
Islet Activating Protein (IAP) Derived from the Culture Supernatant Fluid of Bordetella Pertussis: Effect on Spontaneous Diabetic Rats
}

\author{
T. Toyota ${ }^{1}$, M. Kakizaki ${ }^{1}$, K. Kimura ${ }^{2}$, M. Yajima ${ }^{3}$, T. Okamoto ${ }^{3}$, and M. Ui ${ }^{3}$ \\ ${ }^{1}$ Third Department of Internal Medicine, Tohoku University School of Medicine, Sendai, \\ 2Third Department of Internal Medicine, Hirosaki University School of Medicine, Hirosaki, \\ and ${ }^{3}$ Department of Physiological Chemistry, Faculty of Pharmaceutical Science, Hokkaido University, Sapporo, Japan
}

Summary. The early phase of insulin secretion to an oral glucose load was blunted in spontaneous diabetic rats. The blunted insulin secretion was associated with markedly impaired glucose tolerance. A single injection of the islet activating protein (IAP), a protein derived from the culture medium of Bordetella pertussis, into the spontaneous diabetic rats normalised glucose tolerance. The increase in insulin response to glucose was an important contributing factor to the improvement of glucose tolerance. This curative effect of the IAP on the diabetic state was of long duration; glucose tolerance remained virtually normal over a period of one month in the diabetic rats. Perfusion of the isolated pancreas of the diabetic rats pretreated with IAP showed an increase in insulin response to glucose and loss of suppression of glucagon secretion by noradrenaline.

Key words: Pertussis vaccine, islet activating protein, insulin, glucagon, perfused pancreas, spontaneous diabetic rats.

A hypoglycaemic effect of Bordetella pertussis vaccine in mice was first reported by Parfentjev and Schleyer [1]. Szentivanyi et al. [2] reported that andrenaline-induced hyperglycaemia was prevented in mice pretreated with pertussis vaccine. Injection of the vaccine caused hypoglycaemia in rats, guinea pigs, rabbits and dogs $[3,4]$. The attenuation of andrenaline-induced hyperglycaemia in mice treated with the vaccine could result, partly, from altered pancreatic insulin release [5]. The injection of the vaccine also facilitated insulin release by isoprenaline [6], and enhanced the activity of andrenergic beta receptors insofar as insulin secretion was concerned $[7,8]$.

The administration of the pertussis vaccine to insulin-resistant diabetic patients has been shown to result in a temporary beneficial therapeutic effect, usually lasting for 3-6 weeks [9].

Ui et al. [10] extracted a protein fraction from culture supernatant fluids of Bordetella pertussis. This protein, named islet activating protein (IAP) by them, has a hypoglycaemic effect when injected intravenously in rats. The present work was undertaken to study the antidiabetic effect of IAP in spontaneous diabetic rats $[11,12]$ and to determine whether the action of IAP could be mediated through effects on the secretion of insulin and glucagon by the pancreas.

\section{Methods and Materials}

\section{Islet Activating Protein (IAP)}

IAP was purified from the culture media of Bordetella pertussis phase 1 (Tohama strain) according to the procedures described elsewhere $[10,13]$.

In brief, the active protein in the cell free supernatant of the 48-hour culture media was purified by sequential application of chromatographic separation techniques on columns of hydroxyapatite, carboxymethylcellulose and concanavalin A-sepharose. Each column was washed with phosphate buffer and the protein fraction exhibiting the IAP activity was eluted with $0.5 \mathrm{~mol} / 1 \mathrm{NaCl}$ (phosphate buffered) with a sharp peak. After the final gelfiltration through the Biogel P-100 column, the active protein was found to be homogeneous showing a single band on polyacrylamide gel electrophoresis as well as on 
Ouchterlony double immunodiffusion. The IAP thus purified possessed a molecular weight of 77000 , and an isoelectric point of $\mathrm{pH} 7.8$.

\section{Spontaneous Diabetic Rats}

The spontaneous diabetic rats were obtained by the repetition of selective breeding described elsewhere $[11,12]$. They had free access to water and commercial chow (Japan Clea Co.). Male rats of $\mathrm{F}_{8}$ and $\mathrm{F}_{9}$ with diabetic glucose tolerance were used for this study when they gained a body weight of $300-400 \mathrm{~g}$.

\section{Oral Glucose Tolerance Test (GTT)}

Oral glucose tolerance tests were performed the morning after an overnight fast. Glucose $(500 \mathrm{~g} / \mathrm{l}$, $2 \mathrm{~g} / \mathrm{kg}$ body weight) was administered into the stomach of the rats through a metal tube. Tail vein blood specimens for determination of blood glucose and plasma insulin were obtained prior to the administration of glucose and $15,30,60,90$ and 120 min after glucose.

\section{Pancreas Perfusion}

Normal male rats of Wistar strain and the spontaneous diabetic rats were employed in these experiments. The pancreas was isolated using the procedure described by Grodsky et al. [14] with some modifications $[15,16]$. Under anaesthesia (pentobarbital sodium, $45 \mathrm{mg} / \mathrm{kg}$ body weight), the abdominal cavity was opened. The stomach and the spleen were removed without bleeding. The pancreas was isolated together with the proximal portion of the duodenum. After the isolated pancreas was placed in an incubator, the perfusion was started through a plastic cannula inserted into the coeliac artery. The perfusate was not recycled. Flow rate was maintained constant between 1.8 and $2.0 \mathrm{ml}$ per minute, and the pressure was $50-100 \mathrm{mmHg}$. The perfusion medium was Krebs Ringer bicarbonate buffer containing dex$\operatorname{tran}(4.5 \%)$ and glucose $(3.8 \mathrm{mmol} / 1)$. The medium was gassed with a mixture of $95 \% \mathrm{O}_{2}$ and $5 \% \mathrm{CO}_{2}$, resulting in $\mathrm{pH}$ 7.4. Arterial $\mathrm{pO}_{2}$ was 300-350 $\mathrm{mmHg}$ and portal $\mathrm{pO}_{2}$ was $150-200 \mathrm{mmHg}$. The approximate difference in oxygen tension across the pancreas was $100 \mathrm{mmHg}$. In all experiments a sample of $2 \mathrm{ml}$ was collected from the cannula in the portal vein at suitable intervals, indicated in the figures. Immediately after sampling, the tubes containing $2 \mathrm{ml}$ of the perfusate, with $0.1 \mathrm{ml}$ of aprotinin (Trasylol ${ }^{\circledR}$, Bayer, GRF) were kept at $0-4^{\circ} \mathrm{C}$ and stored at $-20^{\circ} \mathrm{C}$ for a week until analysis.

\section{Experimental Design}

\section{Glucose Tolerance in the Spontaneous Diabetic Rats with Injection of IAP}

Fifteen diabetic rats $\left(\mathrm{F}_{8}\right)$ weighing a mean of $376 \mathrm{~g}$ $(300-400 \mathrm{~g})$ were given glucose solution orally after overnight fasting. Nine of the diabetic rats were intravenously injected with IAP $(10 \mu \mathrm{g} / \mathrm{kg}$ body weight) dissolved in distilled water. On the $3 \mathrm{rd}$ and 35 th days after the injection of IAP, GTT was performed. Two of nine diabetic rats treated with IAP were sacrificed for histological examination. The six other diabetic rats given $0.154 \mathrm{~mol} / 1$ saline instead of IAP were used as controls for the GTT.

\section{Insulin and Glucagon Secretion from the Perfused Pancreas}

(a) Fifteen diabetic rats $\left(F_{9}\right)$ were divided into two groups: 6 rats served as controls and 9 rats were injected with IAP $(5 \mu \mathrm{g} / \mathrm{kg}$ body weight). Within three days of IAP treatment, pancreases from the 9 diabetic rats were perfused. Pancreases from the other 6 diabetic rats were perfused as controls.

(b) Four normal rats on the 3rd day after injection of IAP ( $5 \mu \mathrm{g} / \mathrm{kg}$ body weight) and 6 normal rats without any treatment were subjected to the perfusion experiments.

About $10 \mathrm{~min}$ after the start of the perfusion of the isolated pancreas, the concentration of glucose was changed from $3.8 \mathrm{mmol} / 1$ to $11 \mathrm{mmol} / 1$, and maintained for $10 \mathrm{~min}$. Thereafter, glucose concentration was decreased from $11 \mathrm{mmol} / \mathrm{l}$ to $3.8 \mathrm{mmol} / \mathrm{l}$. Ten minutes after the glucose concentration was maintained at $3.8 \mathrm{mmol} / 1$, norepinephrine $(0.5 \mu \mathrm{g} /$ $\mathrm{ml}$ ) was infused for $10 \mathrm{~min}$, as illustrated in Figure 2.

\section{Analyses}

Glucose was measured by the glucose oxidase method using Glucostat (Worthington Biochemical Co., Freehold, New Jersey). Insulin was measured by the double antibody method [17] using ${ }^{125}$ I-insulin. Rat insulin (Novo Research Institute) was used as a standard and the results were expressed pmol/l. Glucagon was measured by radioimmunoassay using ${ }^{125} \mathrm{I}$-glucagon and dextran charcoal separation [15]. Antibody serum directed against glucagon crossreacts with enteroglucagon and was provided by courtesy of Dr. Koga of Shimizu Pharmaceutical Laboratory. Sensitivity for measurement of insulin and glucagon, defined as the minimal detectable concentration, was $30 \mathrm{pmol} / 1$ and $3 \mathrm{pmol} / 1$, respectively. 
Statistical evaluations were done using Student's t-test. Calculation of sum of insulin during GTT as well as of blood glucose was performed as follows: summation of six points-values during GTT.

\section{Results}

\section{Normalization of Glucose Tolerance in the Diabetic Rats Treated with Injection of IAP (Fig. 1)}

All the spontaneous diabetic rats showed a peak value of blood glucose above $180 \mathrm{mg} / 100 \mathrm{ml}$ and 2hour, value above $140 \mathrm{mg} / 100 \mathrm{ml}$ during GTT. The sum of blood glucose concentrations during the GTT was $1012 \pm 50 \mathrm{mg} / 100 \mathrm{ml} / 2 \mathrm{~h}$ (mean $\pm \mathrm{SE}$ ), which was more than the normal value of $430 \pm 5 \mathrm{mg}$ / $100 \mathrm{ml} / 2 \mathrm{~h}(\mathrm{P}<0.01)$.

In the diabetic rats, plasma insulin in the fasting state was $178 \pm 32 \mathrm{pmol} / \mathrm{l}$, with a peak value of 383 $\pm 55 \mathrm{pmol} / 1$ at $120 \mathrm{~min}$ during the GTT. The plasma insulin of the diabetic rats at 15 min during the GTT was $277 \pm 47 \mathrm{pmol} / \mathrm{l}$, which was less than that of the normal rats ( $426 \pm 24 \mathrm{pmol} / \mathrm{l})$.

On the 3rd and 35th days after injection of IAP, glucose tolerance was virtually normal in the diabetic rats. The sum of blood glucose concentrations was $482 \pm 27 \mathrm{mg} / 100 \mathrm{ml} / 2 \mathrm{~h}$ on the $3 \mathrm{rd}$ day and $564 \pm$ $22 \mathrm{mg} / 100 \mathrm{ml} / 2 \mathrm{~h}$ on the 35 th day (Table 1 ).

Plasma insulin on the 3rd day after IAP-injection in the fasting state was $403 \pm 55 \mathrm{pmol} / 1$ which was more than that of $178 \pm 32 \mathrm{pmol} / \mathrm{l}$ before IAP-injection $(\mathrm{P}<0.01)$. The peak value of plasma insulin was $627 \pm 87 \mathrm{pmol} / \mathrm{l}$ at $90 \mathrm{~min}$ during GTT on the 3rd day. The sum of plasma insulin concentrations during GTT was $3247 \pm 369 \mathrm{pmol} / 1 / 2 \mathrm{~h}$ on the $3 \mathrm{rd}$ day, which was a twofold increase $(P<0.01)$. However, the sum of the plasma insulin concentrations returned to $1689 \pm 204 \mathrm{pmol} / \mathrm{/} / 2 \mathrm{~h}$ by the 35 th day (Table 1). The spontaneous diabetic rats treated with saline showed no changes of pattern of plasma insulin and blood glucose during GTT.

\section{Effect of IAP-Treatment on Insulin Response to Glucose in the Normal Rats (Fig. 1)}

On the 3rd day after injection of IAP $(10 \mu \mathrm{g} / \mathrm{kg}$ body weight) in 6 normal rats, peak value of plasma insulin of $719 \pm 48 \mathrm{pmol} / \mathrm{l}$ at $15 \mathrm{~min}$ during GTT was significantly more than that of $426 \pm 43 \mathrm{pmol} / 1$ before the treatment, while the glucose tolerance remained normal after injection of IAP.

\section{Insulin and Glucagon Secretion by the Perfused Pancreas of the Spontaneous Diabetic Rats and Normal Rats with Injection of IAP (Fig. 2)}

Insulin secretion by the normal rat pancreas responded to continuous glucose infusion $(11 \mathrm{mmol} / \mathrm{l})$ in a biphasic manner. The first phase of insulin secre-
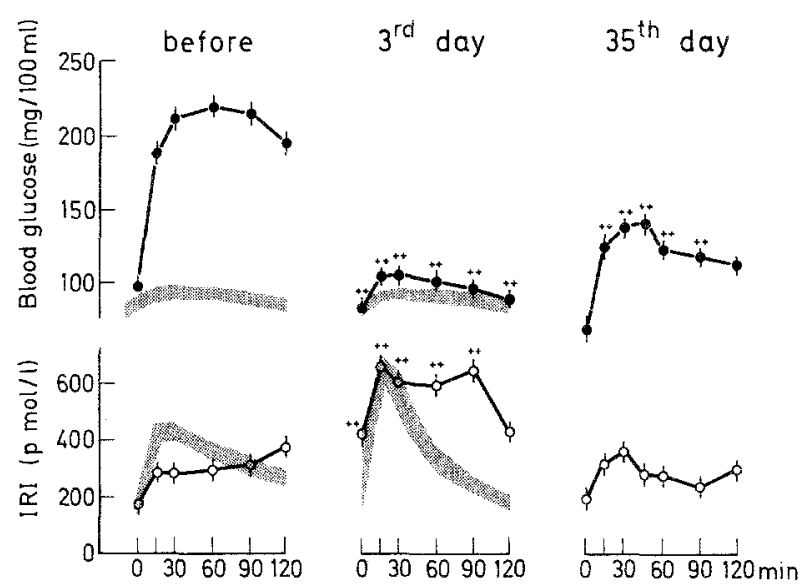

Fig. 1. Normalization of glucose tolerance after IAP-injection into spontaneous diabetic rats. The values are presented as the mean of 7 experiments \pm SEM. $++P<0.01$ vs the value before IAPinjection. The dotted shadow shows the results of 6 normal rats before and after IAP-injection

Table 1. Sum of 6 points-values for blood glucose and plasma insulin during GTT

\begin{tabular}{|c|c|c|c|c|c|}
\hline & \multicolumn{2}{|c|}{ Before IAP-injection } & \multicolumn{2}{|l|}{ 3rd day } & \multirow{2}{*}{$\begin{array}{l}\text { 35th day } \\
\text { Diabetic rats } \\
\text { (7) }\end{array}$} \\
\hline & $\begin{array}{l}\text { Normal rats } \\
\text { (6) }\end{array}$ & $\begin{array}{l}\text { Diabetic rats } \\
(7)\end{array}$ & $\begin{array}{l}\text { Normal rats } \\
\text { (6) }\end{array}$ & $\begin{array}{l}\text { Diabetic rats } \\
\text { (7) }\end{array}$ & \\
\hline $\begin{array}{l}\text { Blood glucose } \\
\text { (mg/100 ml/2h) } \\
\text { Plasma insulin }\end{array}$ & $430 \pm 5$ & $1012 \pm 50$ & $433 \pm 8$ & $\begin{array}{c}482 \pm 27^{\mathrm{a}} \\
3247 \pm 369^{\mathrm{a}}\end{array}$ & $564 \pm 22^{a}$ \\
\hline
\end{tabular}

Mean \pm S. E.

Blood glucose and plasma insulin levels during GTT as illustrated were calculated by summation of 6 points-values.

a shows p-value $<0.01$ vs. the values before the IAP-injection 

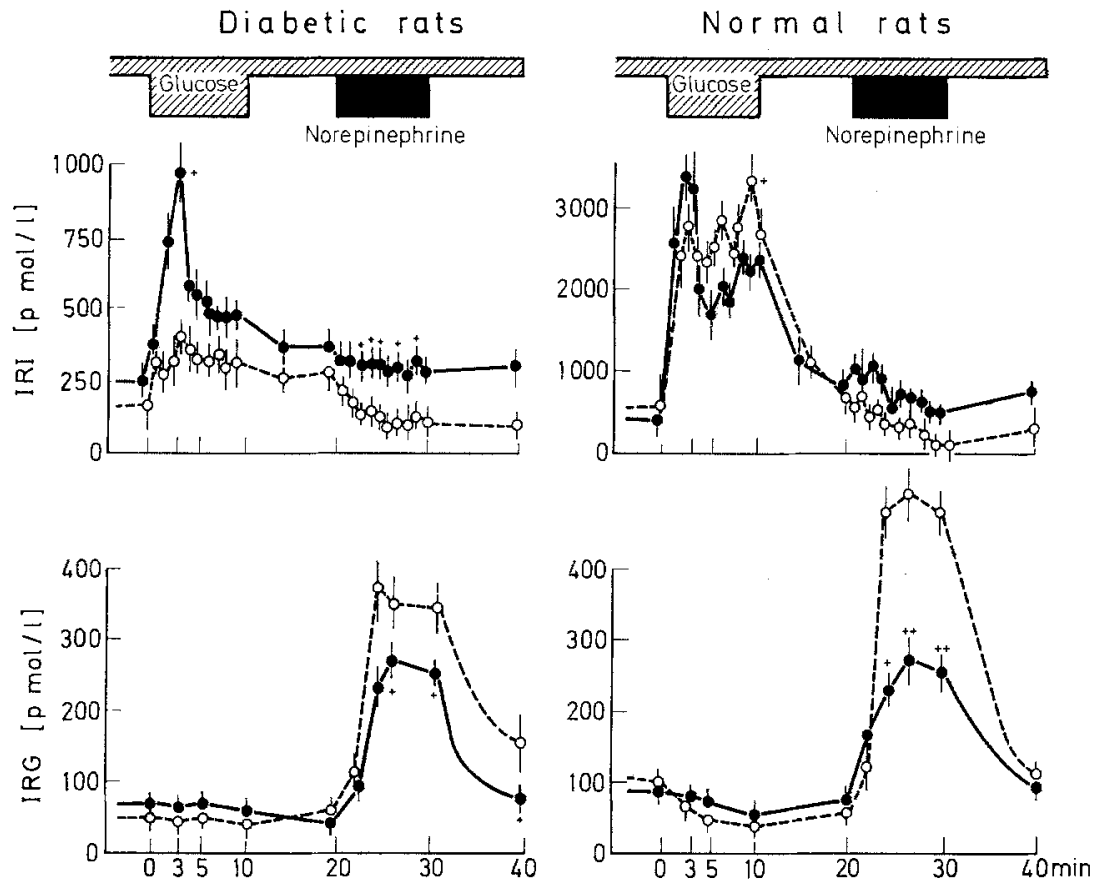

Fig. 2. Insulin (upper half) and glucagon (lower half) secretion by the isolated pancreas of normal rats (right side) and diabetic rats (left side) treated with IAP-injection $(-)$ ) or without IAP-injection (O--.-O). $+\mathrm{P}<0.05++\mathrm{P}<0.01$ vs the value of IAP-untreated rats. Glucose concentration for stimulation of insulin release was $11 \mathrm{mmol} / \mathrm{l}$. Noradrenaline $(0.5 \mu \mathrm{g} / \mathrm{ml})$ was infused in this experiment. The results are presented as the mean \pm SEM of 9 diabetic rats with IAP-injection and of 6 diabetic rats without the injection. Four normal rats with IAP-injection and 6 normal rats without the injection are used for the perfusion experiments tion was increased slightly by pretreatment of the normal rats with IAP. The stimulatory effect of noradrenaline on glucagon secretion was partially blocked by pretreatment with IAP.

In the diabetic rats the sudden rise in glucose concentration did not elicit a recognizable first phase of insulin release. Pretreatment of the diabetic rats with IAP, however, restored the first phase. The insulin values at 23,24, 25, 27 and 29 min during infusion of noradrenaline were significantly greater in IAPtreated diabetic rats than in untreated diabetic rats $(\mathrm{P}<0.05)$. The inhibition of insulin secretion by noradrenaline seemed again partially blocked.

In both the diabetic rats and the normal rats treated with IAP, the glucagon secretion in response to noradrenaline was only half as great as in the rats untreated with IAP (Fig. 2).

\section{Discussion}

Pertussis vaccine has effects on normal animals apart from provoking antibody production [8]. The pertussis-sensitized animals behave as though the beta andrenergic receptors are blocked [2, 19, 20,21]. An explanation for the in vivo production of beta adrenergic blockage by Bordetella pertussis was provided by Morse $[18,22]$, who stated that a substance in culture supernatant fluids of Bordetella pertussis inhibited the increment of intracellular cyclic AMP in lymphocytes produced by isoprenaline and methacholine.
Among the various effects, the action of the vaccine in lowering blood glucose has been of interest to us. In the pertussis-sensitized animals, hypoglycaemia appeared to be caused by an increase in peripheral uptake of glucose $[3,5,23]$ and by a decrease in hepatic phosphorylase activity [24]. Dhar et al. [9] reported that in insulin-resistant diabetic patients the pertussis vaccine succeeded in reducing blood glucose concentration for several weeks.

These experimental and clinical studies suggest that some factor(s) of Bordetella pertussis have a hypoglycaemic effect. In the present study IAP is proved to be one of the hypoglycaemic factors derived from the culture supernatant fluids of Bordetella pertussis. The glucose tolerance curve in the diabetic rats returned to normal on the 3 rd day after injection of IAP, accompanied by hyperinsulinaemia. Glucose tolerance remained virtually normal until the 35th day after injection of IAP, while insulin response to glucose closely approached the pretreatment level.

Using the perfusion technique, in which the pancreas was isolated in the diabetic rats, the first phase of insulin secretion after a glucose stimulus was restored by pretreatment with IAP. However, IAP per se does not directly stimulate insulin secretion from the perfused pancreas of normal rats (unpublished data).

The first mechanism of IAP in reducing blood glucose appears to relate to an increase in insulin secretion. Adrenergic receptors in the endocrine pancreas may be modified by IAP, in that treatment 
of the diabetic rats with IAP blocked both the inhibitory effect of noradrenaline on insulin secretion and the stimulatory effect on glucagon secretion.

The second mechanism of IAP appears to be due to enhanced glucose utilization peripherally. Glucose utilization is dependent partly upon the state of insulin receptors in membrane of cells, which is variable [25]. For example, nonimmune human circulating blood T-lymphocytes do not have a demonstrable receptor for insulin, but the insulin receptor appears as a consequence of T-cell activation [26]. It has not been proved that injection of IAP stimulates immune activity, but it is possible that some effects of IAP may be mediated through on immune reaction. Further study is necessary to elucidate fully the mechanism of IAP.

Acknowledgement. This work was supported in part by grants (No. 157/69, 257/68) from the Ministry of Education of Japan.

\section{References}

1. Parfentjev, L.A., Schleyer, W. L.: The influence of histamine on the blood sugar level of normal and sensitized mice. Arch. Biochem. Biophys. 20, 341-346 (1949)

2. Szentivanyi, A., Fishel, C.W., Talmage, B.W.: Adrenaline mediation of histamine and serotonin hyperglycaemia in normal mice and the absence of adrenaline-induced hyperglycaemia in pertussis-sensitized mice. J. Infect. Dis. 113, 86-98 (1963)

3. Dhar, H.L., Sanyal, R. K.: Carbohydrate metabolism and anaphylaxis. J. Pharm. Pharmacol. 15, 628 (1963)

4. Dhar, H.L., West, G. B.: Sensitization procedures and the blood sugar concentration. J. Pharm. Pharmacol. 24, 249-250 (1972)

5. Gulbenkian, A., Schobert, L., Nixon, C., Tabachnick, I. I. A.: Metabolic effects of pertussis sensitization in mice and rats. Endocrinology 83, 885-892 (1968)

6. Tabachnik, I. I. A., Gulbenkian, A.: Adrenergic changes due to pertussis: insulin, glucose and free fatty acids. Eur. J. Pharmacol. 7, 186-195 (1969)

7. Sumi, T., Ui, M.: Potentiation of the adrenergic beta-receptormediated insulin secretion in pertussis-sensitized rats. Endocrinology 97, 352-358 (1975)

8. Katada, T., Ui, M.: Accelerated turnover of blood glucose in pertussis-sensitized rats due to combined actions of endogenous insulin and adrenergic beta-stimulation. Biochem. Biophys. Acta 421, 57-69 (1976)

9. Dhar, H. L., Dhirwani, M.K., Shethe, U. K.: Pertussis vaccine in diabetics requiring high dose insulin. Br. J. Clin. Pract. 29, 119-120 (1975)

10. Ui, M., Mizushima, Y., Kambayashi, Y., Yajima, M.: Extraction and purification of islet activating protein from the culture supernatant fluids of Bordetella pertussis (Jap.). J. Jpn. Diabetic Soc. 20, (Suppl.), 22 (1977)

11. Goto, Y., Kakizaki, M., Masaki, N.: Spontaneous diabetes produced by selective breeding of normal Wistar rats. Proc. Jpn. Acad. 51, 80-85 (1975)
12. Goto, Y., Kakizaki, M., Toyota, T., Masaki, N., Kitahara, A., Yagihashi, S., Kimura, K.: Spontaneous diabetes produced by repeated selective breeding of normal Wistar rats. In: IXth Congress of the International Diabetes Federation. Excerpta Medica Congr. Ser. No. 413, 519-526 (1977)

13. Yajima, M., Hosoda, K., Kanbayashi, Y., Nakamura, T., Nogimori, K., Mizushima, Y., Nakase, Y., Ui, M.: Isletactivating protein (IAP) in Bordetella pertussis that potentiates insulin secretory responses of rats: Purification and characterization. J. Biochem. (Tokyo) 83, 295-303 (1978)

14. Grodsky, G.M., Batts, A.A., Bennett, L.L., Vcella, C., McWilliams, N. B., Smith, D.F.: Effects of carbohydrates on secretion of insulin from isolated rat pancreas. Am. J. Physiol. 205, 638-644 (1963)

15. Toyota, T., Sato. S., Kudo, M., Abe, K., Goto, Y.: Secretory regulation of endocrine pancreas: Cyclic AMP and glucagon secretion. J. Clin. Endocrinol. Metab. 41, 81-89 (1975)

16. Toyota, T., Abe, K., Kudo, M., Goto, Y.: Effects of trypsin on glucose-induced insulin secretion from the perfused rat pancreas. Tohoku J. Exp. Med. 118, 381-385 (1976)

17. Morgan, C. R., Lazarow, A.: Immunoassay of insulin using a two-antibody system. Proc. Soc. Exp. Biol. Med. 110, 29-32 (1962)

18. Morse, S. I.: Bordetella pertussis and beta adrenergic blockage. In: W. Braun, L. M. Lichenstein, C. W. Parker (ed.): Cyclic AMP, Cell Growth and the Immune Response. Berlin, Heidelberg, New York: Springer 263-269 1974

19. Fishel, C.W., Szentivanyi, M.K., Talmage, D.W.: Sensitization and desensitization of mice to histamine and serotonin by neurohumors. J. Immunol. 89, 8-18 (1962)

20. Fishel, C.W., Szentivanyi, A.: The absence of adrenalineinduced hyperglycaemia in pertussis-sensitized mice and its relation to histamine and serotonin hypersensitivity. J. Allergy Clin. Immunol. 34, 439-454 (1963)

21. Pieroni, R. E., Bundeally, A.E., Amdar, M.O., Levine, L.: Bordetella pertussis as a beta adrenergic blocking agent. Int. Arch. Allergy Appl. Immunol. 41, 637-647 (1971)

22. Morse, S.I., Morse, J.H.: Isolation and properties of the leukocytosis- and lymphocytosis-promoting factor of Bordetella pertussis. J. Exp. Med. 143, 1483-1502 (1976)

23. Dhar, H. L., Sanyal, R. K., West, G. B.: The relationship of the blood sugar level to the severity of anaphylactic shock. Br. J. Pharmacol. 31, 351-355 (1967)

24. Kreutner, W., Gulbenkian, A., Tabachnik, I.I. A.: Effect of epinephrine on hepatic glycogen phosphorylase and synthetase activities in normal and pertussis-sensitized rat. Biochem. Pharmacol. 19, 2561-2567 (1970)

25. Davidson, M. B., Kaplan, S. A.: Increased insulin binding by hepatic plasma membrane from diabetic rats. Normalization by insulin therapy. J. Clin. Invest. 59, 22-30 (1977)

26. Helderman, J.H., Strom, T.B.: Emergence of insulin receptors upon alloimmune T-cells in the rats. J. Clin. Invest. 59, 338-344 (1977)

Received: September 19, 1977,

and in revised form: December 19, 1977

T. Toyota

Third Department of Internal Medicine

Tohoku University School of Medicine Sendai PO 980

Japan 